\title{
Introduction to the TAIGER special issue of Marine Geophysical Research
}

\author{
Kirk D. McIntosh • Char-Shine Liu • \\ Chao-Shing Lee
}

Received: 11 February 2013/Accepted: 15 February 2013/Published online: 2 March 2013

(C) Springer Science+Business Media Dordrecht 2013

With the advent of the plate tectonics paradigm in the 1960s and 1970s, Earth scientists began to understand mountain-building, basin formation, earthquakes and a myriad other processes that shape our world in terms of moving plates and deformation focused along their boundaries. In this period, early adopters such as Chai (1972), Biq (1972), and Wu (1978) recognized that Taiwan was formed by a special process: the collision of an island arc with a continental margin. This is the special or terminal case of subduction where the ocean basin floored by the subducting plate is completely consumed and the advancing arc and forearc make contact with the continental margin. While this general idea to understand Taiwan has stood the test of time and remains valid, the quest to better understand how arc-continent collision works has continued. As one of the few sites of active arccontinent collision on the Earth today, Taiwan has continued to be one of the "type" study areas for this process.

The TAIGER (TAiwan Integrate GEodynamic Research) project was developed to again use the Taiwan area as a natural laboratory to reveal the evolution and lithospheric structure of an ongoing collision. While previous work in the Taiwan area had been fruitful, improved instrumentation and analysis techniques available for TAIGER and the lessons

K. D. McIntosh $(\bowtie)$

Institute for Geophysics, University of Texas at Austin, Austin, TX 78758, USA

e-mail: kirk@ig.utexas.edu

\section{C.-S. Liu}

Institute of Oceanography, National Taiwan University, Taipei, Taiwan, ROC

C.-S. Lee

Institute of Applied Geosciences, National Taiwan Ocean University, Keelung, Taiwan, ROC learned elsewhere in the world suggested that significant progress could be made. The concept behind TAIGER was to use a dense passive seismic network onshore in Taiwan to determine full crustal and lithospheric structure, and to use active-source seismology, onshore with explosive sources, offshore with airgun sources, plus offshore to onshore recording, to develop more detailed models of crustal structure and images of crustal deformation. With the generous support of the United States National Science Foundation Continental Dynamics program, Taiwan's National Science Council, Ministry of the Interior, and Central Geological Survey of the Ministry of Economic Affairs, the TAIGER project became the largest coordinated geophysical effort to study the tectonics of Taiwan and evolution of arc-continent collision in this vicinity. Figure 1 shows most instrument locations for passive and active seismic recording as well as seismic acquisition ship tracks followed by the R/V Marcus Langseth during the TAIGER project. The marine, active-source data acquisition took place during three $\mathrm{R} / \mathrm{V}$ Langseth cruises, MGL0905, MGL0906, and MGL0908, starting in 1 April 2009 and ending in 25 July 2009. A shorter, 8-day cruise, MGL0907, occurred during 7-14 June 2009 to recover 20 broad band ocean bottom seismographs (OBS) that had been deployed a year earlier from the R/V Melville. Determining crustal structure across Taiwan and in a wide area surrounding was a prime objective for TAIGER. Thus $\sim 269$ OBS stations and 243 land stations were deployed and more than $10,000 \mathrm{~km}$ of multichannel seismic reflection (MCS) data were recorded. In addition, there were 10 other ships working together with the R/V Langseth at various times during the TAIGER marine surveys for the OBS deployments and recoveries, including Taiwanese research vessels, fishing boats, tourist ships, and others.

As seen in Fig. 1, the TAIGER project targeted all aspects of the arc-continent collision. The particular advantages of 


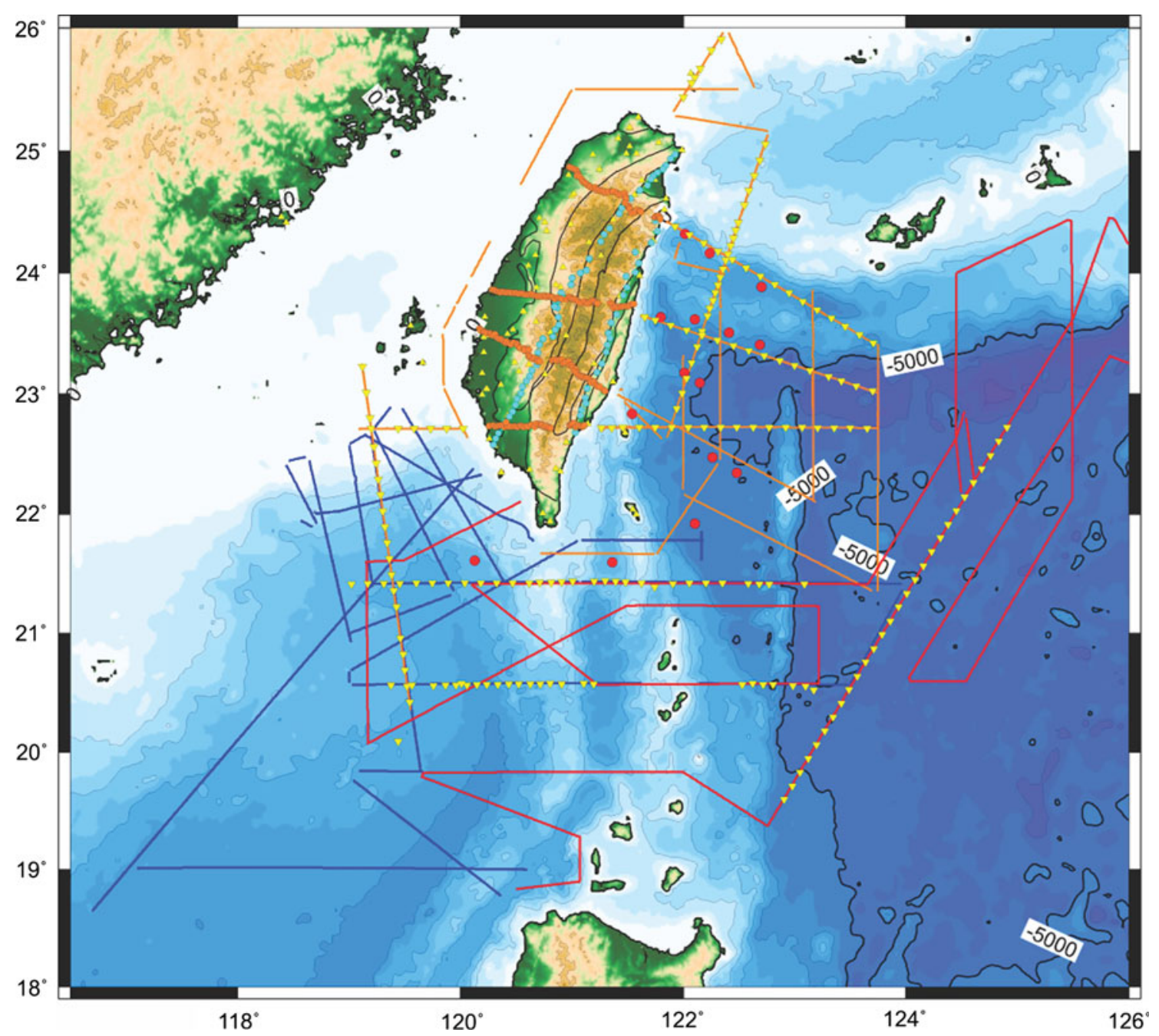

Fig. 1 Map of TAIGER passive and active instrument locations and marine, active-source ship tracks and seismic profiles. Red dots are marine broadband OBS stations, yellow triangles are active-source OBS locations, and orange, turquoise, and yellow symbols on Taiwan

studying this process in the Taiwan area are that the process is still active and that different nearby areas can be studied to understand the evolution of the collision. Substantial effort was focused on the area west and southwest of Taiwan, including the shelf, slope and deeper basin. These areas are future locations of underthrusting and full collision, presumably analogous to what existed to the northeast before collision, so they represent a pre-collision state of the Eurasia plate margin and last remnant of the consumed northeast portion of the South China Sea. Another focus of data acquisition was south of Taiwan, including the Manila trench, North Luzon Arc, and the Hengchun Ridge accretionary prism. By covering this area from south to north, the TAIGER data set provides an opportunity to document changes in crustal structure and tectonics in the transition from subduction to collision. Still farther north, the program was dominated by onshore/offshore profiling to reveal the are TAIGER short-period and broadband seismic stations. The blue, orange, and red track lines correspond to cruises MGL0905, MGL0906, and MGL0908, respectively

evolution of collision, including uplift of the southern Central Range, emergence of the Coastal Range, and the post-mature collision structure of northern Taiwan. Many of the onshore/offshore transects were purposely extended to the east to cross the enigmatic Gagua Ridge. Lastly, many seismic profiles were acquired across the Ryukyu Trench and forearc, an area that holds evidence for the initial location of North Luzon arc contact with the Eurasia continental margin.

The collection of papers in this special issue of Marine Geophysical Research represent some of the early results from the TAIGER project and also include complementary works from other data sets in the vicinity of Taiwan. Lester and McIntosh present a survey of MCS data examples from a variety of areas sampled by TAIGER. Different areas have particular noise problems and imaging objectives, but most data have strong contamination from water-bottom and 
other multiple reflections. This paper shows some of the techniques used to suppress multiples in this data set and shows some of the intriguing images that have resulted from careful seismic processing. The contribution from Yeh et al. also demonstrates the high quality of well processed TAIGER seismic reflection data. This work concentrates on the area southwest of Taiwan and examines the nature of the crust west of the Manila trench, using both seismic reflection data and magnetic data analysis and modeling. On the other hand, the paper from Deng et al. describes modeling results from OBS travel time modeling offshore southwestern Taiwan. These investigators modeled 3 TAIGER OBS transects to determine crustal velocity structure. To take this a step further they used these results and then added another TAIGER model and a pre-existing velocity model to develop a pseudo 3-D velocity model from five intersecting transects. This work reveals a thin crust zone near the base of the continental slope southwest of Taiwan, part of which has been underthrust at the Manila trench. They also determine a widespread occurrence of highvelocity lower crust $(>7 \mathrm{~km} / \mathrm{s})$ in this area.

Using the TAIGER seismic reflection profiles together with the bathymetry and free air gravity anomaly data, Chang et al. focused on outer rise flexure of the South China Sea crust subducting at the Manila Trench north and west of Luzon Island to estimate variations in elastic thickness of the subducting plate. These authors also explore the relationship between elastic thickness and age of a subducting plate and find that the thickness and age at the southern Manila trench is consistent with published relationships. East of the Manila trench, the paper by
Armada et al. investigates the possible extension of the Philippine fault zone north of Luzon Island and into the offshore forearc region. A combination of bathymetry and seismic reflection data suggests that this key regional fault may feed into the subduction system to the north.

Two of the most critical factors in sedimentary and crustal deformation are the availability of fluids and the temperature structure. The contribution from Chen et al. uses seismic reflection data from southwest of Taiwan to track variations in the geothermal gradient patterns, based on the depth of the bottom-simulating reflector (BSR), and to derive estimates of vertical fluid flow in these areas. According to this analysis, vertical fluid flow appears highest near the trench and increases as the continental slope is underthrust at the northern Manila trench. A complementary paper from Wang et al. describes a detailed analysis of sedimentary seismic pressure-wave velocities using OBS data from the northern South China Sea. These investigators image the BSR with single channel seismic reflection data and use OBS data to determine a velocity profile for depth conversion.

\section{References}

Biq C-C (1972) Dual-trench structure in the Taiwan Luzon region. Proc Geol Soc China 15:66-75

Chai BHT (1972) Structure and tectonic evolution of Taiwan. Am J Sci 272:389-422

Wu FT (1978) Recent tectonics of Taiwan. J Phys Earth 26(supplement):S265-S299 